\title{
El Proyecto UNA Educación de Calidad en el contexto de la COVID-19
}

\author{
The UNA Quality Education Project in the Context of COVID-19
}

O Projeto de Educação da Qualidade da UNA no contexto do COVID-19

\section{Angélica Fontana-Hernández}

Universidad Nacional

ROR:: https://ror.org/01t466c14 Centro de Investigación y Docencia en Educación

División de Educación Básica angelica.fontana.hernandez@una.cr https://orcid.org/0000-0001-5168-9774

Shantal Herrera-Sibaja

Universidad Nacional

ROR:: https://ror.org/01t466c14 Centro de Investigación y Docencia en Educación

División de Educación Básica shantalhs22@gmail.com

(iD) https://orcid.org/0000-0002-3714-1857

Brenda Leiva-Durán

Universidad Nacional

ROR:: https://ror.org/01t466c14 Centro de Investigación y Docencia en Educación

División de Educación Básica brenda.leiva.duran@est.una.ac.cr

(iD) https://orcid.org/0000-0002-0689-2113

Jennifer Montero-Cascante

Universidad Nacional

ROR:: https://ror.org/01t466c14

Facultad de Ciencias Sociales

Escuela de Secretariado Profesional jennifer-0515@hotmail.es

iD https://orcid.org/0000-0001-5920-1016

Resumen: Esta reflexión presenta la reorganización en la dinámica del Proyecto UNA Educación de Calidad en el contexto del COVID-19 con el fin de proporcionar acompañamiento al estudiantado con discapacidad en la formación universitaria.

Palabras claves: Apoyo educativo; discapacidad; educación superior; COVID-19. 
https://doi.org/10.15359/ree.24-S.12

https://www.revistas.una.ac.cr/index.php/educare

educare@una.ac.cr

\begin{abstract}
This reflection presents the reorganization in the dynamics of the UNA Quality Education Project in the context of COVID-9, in order to provide support to students with disabilities in university training.
\end{abstract}

Keywords: Educational support; disability; higher education; COVID-19.

Resumo: Esta reflexão apresenta a reorganização da dinâmica do Projeto de Educação da Qualidade da UNA no contexto do COVID-19, a fim de apoiar os alunos com deficiência na formação universitária.

Palavras-chave: Apoio educacional; deficiência; ensino superior; COVID-19.

Recibido: 14/07/2020 Aceptado: 07/08/2020

\title{
Introducción
}

El Proyecto UNA Educación de Calidad, código 0266-17, está inscrito en la División de Educación Básica del Centro de Investigación y Docencia en Educacío (CIDE) de la Universidad Nacional (UNA), Costa Rica, desde 1998-1999. En su IV Fase: 2018-2020, proporciona apoyo y seguimiento a 30 estudiantes con discapacidad matriculados en distintas carreras de la sede central de la UNA, mediante el trabajo colaborativo con el personal académico y administrativo de las unidades académicas (Fontana, 2017).

\section{Desarrollo}

Desde la dinámica interna del proyecto, el acompañamiento se concibe como aquellas acciones en el ámbito personal, material, organizativo y curricular que generan las condiciones de accesibilidad para la inclusión y participación en forma autónoma y autodeterminada del estudiantado con discapacidad en su formación universitaria.

La nueva realidad nos reta y la logística de trabajo en el proyecto se modifica donde la reconstrucción de las formas de apoyo permite dar continuidad a los procesos de formación universitaria en estrecha relación con la resiliencia académica (Linares Rubí y Quintanar Ramírez, 2012).

La intuición, la vocación, pero principalmente el amor del equipo de trabajo, generaron las ideas necesarias para reconstruir una estrategia que ya veníamos aplicando durante los periodos de matrícula y que denominamos acompañamiento remoto. En el I ciclo 2020 se destacan las siguientes acciones: atención individual para la elaboración de tareas; buscar información para los trabajos finales de graduación (TFG); ingresar al Aula Virtual; revisión del formato, la redacción, la ortografía, las citas textuales y las referencias según Norma APA de trabajos; la digitalización 
https://doi.org/10.15359/ree.24-S.12

de documentos empleando el programa ABBYY FineReader 2015 (versión gratuita); el apoyo en el uso de nuevos recursos tecnológicos (Zoom Meetings, Microsoft Teams, Flipboard, Webinar y otros) en la formación universitaria, en el área emocional y en la matrícula porque la plataforma virtual de la UNA no es accesible.

En este proceso de acompañamiento remoto al estudiantado, es relevante el papel fundamental de la comunicación constante y asertiva entre el estudiantado participante; asimismo, el sentido de pertenencia y apego a la dinámica del proyecto que genera seguridad y confianza para la implementación de la metodología de trabajo. No obstante, un aspecto latente, generado por la virtualización, es la exclusión ya que muchas aplicaciones, programas y recursos tecnológicos son inaccesibles para las personas con discapacidad

Si bien, es determinante el papel esencial que tiene cada estudiante en la construcción de sus vidas, también se refiere a la imbricación con el entrabado social en que se desenvuelve, teniendo el Proyecto UNA Educación de Calidad un rol fundamental en la construcción de la resiliencia del estudiantado participante Forés y Grané (2016).

\section{Conclusión}

A manera de conclusión, al visualizar la diversidad estudiantil, en la formación universitaria mediante la modalidad denominada presencialidad remota con apoyo de recursos tecnológicos, emerge la inquietud por la individualidad, esto por cuanto, los procesos se tornan complejos en el momento en que se deja de considerar las particularidades versus las oportunidades. Lo anterior, pone de manifiesto la exigencia de las condiciones de accesibilidad para garantizar la inclusión, la equidad y la calidad en la formación universitaria para toda la población estudiantil, con la consigna "De no dejar a nadie atrás".

Nota general: Corrección de estilo y traducciones a cargo de las autoras.

\section{Referencias}

Fontana, A. (2017). IV formulación del proyecto: UNA Educación de calidad para el estudiantado de la Universidad Nacional de Costa Rica (código 0266-17). Vicerrectoría de Docencia, Universidad Nacional de Costa Rica.

Forés, A. y Grané, J. (2016). La resiliencia. Crecer desde la adversidad (6. ${ }^{a}$ ed.). Plataforma Actual.

Linares Rubí, B. y Quintanar Ramírez, E. N. (2012). La resiliencia académica y la importancia del apoyo social en adolescentes [Tesis de Licenciatura]. Universidad Pedagógica Nacional, México. http://200.23.113.51/pdf/28442.pdf 